\title{
LEARNING AND MONETARY POLICY IN A SPECTRAL ANALYSIS REPRESENTATION
}

\author{
Andrew Hughes Hallett* \\ Christian R Richter ${ }^{* *}$ \\ "Vanderbilt University, University of Strathclyde, and CEPR, London \\ ${ }^{* *}$ University of Strathclyde, and University of Klagenfurt
}

\begin{abstract}
In this paper, we show how to derive the spectra and cross-spectra of economic times series from the dynamic structure of an underlying econometric model. This allows us to conduct a proper frequency analysis of economic and financial variables on a limited sample of data, without it being ruled out by the large sample requirements of direct spectral estimation. We show, in particular, how this can be done for time-varying models and time-varying spectra. To demonstrate our technique in action, we use it to analyse the behaviour of British interest rates during and following the ERM crisis of 1992/3.
\end{abstract}

Keywords: Time Dependent Spectral Analysis, Behavioural Science, Learning

\section{INTRODUCTION}

A standard paradigm in economics is efficient markets. However many markets have been found to be inefficient. In financial markets this may happen because of "informational inefficiencies", relating to the cost of gathering information, the costs of adjusting to a new equilibrium, or to uncertainty and the process of learning. They may also reflect asymmetries in information (Black, 1989; Easley and O'Hara, 1992). Other markets - typically labour or certain goods markets - may be inefficient because such informational problems cause rigidities in behaviour (Akerlof, 1970).

The dynamics of any financial market should therefore reflect within and between period adjustments to an equilibrium path which is itself adjusting to learning, the resolution of uncertainty, and to information gathering. That will imply different behaviour and different adjustment characteristics at different frequencies, for example in the short run behaviour vs. the longer run convergence pattern of the market as a whole, as agents adjust to eliminate disequilibria in their current positions and adjust their understanding of what their long run (equilibrium) positions should be.

The only way to analyse these different layers of dynamic behaviour, and the relations between them, is to use a spectral analysis in the frequency domain. It is not possible to disentangle the different elements in a time domain representation. Unfortunately, that route has been closed to economists because of the long sample of data required to estimate economic spectra directly. As a rule of thumb, we should have seven to eight times as much data as the longest cycle - assuming the underlying structure to be constant. That is ruled out if learning and information gathering lies at the heart of the convergence process.

The purpose of this paper is to provide a technique for calculating the necessary spectra indirectly. We show how this can be done in the case where the parameters of the underlying market relationships may be time varying. (Laven and Shi, 1993; Nerlove et al., 1995; and Wolters, 1980) have shown how a dynamic regression equation can be used to derive an autorgressive distributed lag model. We apply this technique in a time-varying parameter framework in order to take learning into account. That then allows us to calculate a time-varying spectrum. There are therefore two innovations in this paper: the demonstration that the relevant components for a spectral analysis of financial markets can be extracted from the parameters of a simple dynamic econometric, or VAR model - thereby avoiding the need for the very large samples of data which are required for direct spectral estimation. Second we demonstrate the value of being able to perform spectral analysis on timevarying relationships between financial variables.

This paper is structured as follows: we first describe how results from the time domain an be transferred into the frequency domain. We then present the components from cross spectrum analysis which we need in our analysis. As an example we apply these methods to an equation from Richter (2001), and draw some policy implications for the short-end of the British term structure and how its behaviour has changed since the ERM crisis of 1992. 


\section{THE RELATIONSHIP BETWEEN THE TIME DOMAIN AND THE FREQUENCY DOMAIN}

\subsection{Spectra and Cross-Spectra}

In this paper, we are interested in the relationship between two different variables $\left\{\mathrm{Y}_{\mathrm{t}}\right\}$ and $\left\{\mathrm{X}_{\mathrm{t}}\right\}$, which are usually assumed to be stationary and related in the following way:

$$
Y_{t}=A(L) X_{t}+u_{t}
$$

where $\mathrm{A}(\mathrm{L})$ is a filter and $\mathrm{L}$ is the lag operator, such that $\mathrm{LY}_{\mathrm{t}}=\mathrm{Y}_{\mathrm{t}-1}$. In this case, we have to consider the cross-covariance generating function. The crosscovariance generating function is defined as

(2) $g_{Y X}(z)=\sum_{\tau=-\infty}^{\infty} \gamma_{Y X}(\tau) z^{\tau}$

where $(\mathrm{z})$ is a complex scalar, such that

$$
z=e^{-i \omega}=\cos \omega-i \sin \omega
$$

where $\mathrm{i}^{2}=-1$, and $\omega$ represents the frequency in radians per unit of time. Hence, corresponding to $(2), \gamma_{Y X}(\tau)$ is defined as:

$$
\gamma_{Y X}(\tau)=E\left(Y_{t} X_{t-\tau}\right)
$$

But, if $\left\{Y_{t}\right\}$ follows (1) we can substitute (1) in (4):

$$
\gamma_{Y X}(\tau)=E\left(A(L) X_{t} X_{t-\tau}\right)+E\left(u_{t} X_{t-\tau}\right)
$$

And since $\left\{u_{t}\right\}$ is i.i.d. $\left(0, \sigma^{2}\right)$ and $E\left(u_{t} X_{t-\tau}\right)=0$. Hence, (2) simplifies to

$$
\gamma_{Y X}(\tau)=\sum_{j=0}^{\infty} a_{j} \gamma_{X X}(\tau-j)
$$

In (6) $a_{j}$ is a sequence of coefficients from $A(L)$ and $\gamma_{X X}(\tau-j)=E\left(X_{t} X_{t-\tau-j}\right)$. Hence, the crosscovariances depend on the coefficients $a_{j}$ from (6). If we interpret (6) as an estimated equation, then the cross-covariances all depend on the estimated coefficients of our distributed lag model (6). Consequently, if the estimates obtained for (6) are efficient, then the estimated cross-covariance functions will also be efficient (given knowledge of $\gamma_{\mathrm{XX}}$ ).

The innovation here is that, using estimated coefficients from (6) vastly simplifies estimation of the spectra. Indeed one of the biggest disadvantages of a direct estimation approach is the large number of observations that would be necessary to carry out the necessary frequency analysis. We can get round that disadvantage by starting from regression based estimates as follows. We can write the cross spectral density $\left(\mathrm{g}_{\mathrm{YX}}(\mathrm{z})\right)$ of the exogenous variable as being proportional to the Fourier transform of the lag coefficients (Nerlove et al. , 1995), i.e.

$$
\mathrm{g}_{\mathrm{YX}}(\mathrm{z})=\sum_{\tau=-\infty}^{\infty} \sum_{\mathrm{j}=0}^{\infty} \mathrm{a}_{\mathrm{j}} \gamma_{\mathrm{XX}}(\tau-\mathrm{j}) \mathrm{z}^{\tau}=\mathrm{A}(\mathrm{z}) \mathrm{g}_{\mathrm{XX}}(\mathrm{z})
$$

where $\mathrm{A}(\mathrm{z})$ is the frequency response function, and $|\mathrm{A}(\mathrm{z})|^{2}$ is the transfer function of $\mathrm{A}(\mathrm{L})$. But equation (7) can also be written in terms of the spectra involved. Using the fact that

$$
f_{Y X}(\omega)=\frac{1}{2 \pi} g_{Y X}(z)
$$

and that

$$
f_{X X}(\omega)=\frac{1}{2 \pi} g_{X X}(z)
$$

we get the cross spectrum

$$
\mathrm{f}_{\mathrm{YX}}(\omega)=\mathrm{A}(\mathrm{z}) \mathrm{f}_{\mathrm{XX}}(\omega)
$$

where $A(z)$ is the Fourier transform of the weights $\left\{a_{j}\right\}_{j=-\infty}^{\infty}$. Rearranging (10) yields

$$
A(z)=\frac{f_{Y X}(\omega)}{f_{X X}(\omega)}
$$

Hence equation (11) implies that

$$
|A(z)|=\frac{\left|f_{Y X}(\omega)\right|}{f_{X X}(\omega)}
$$

where $|\mathrm{A}(\mathrm{z})|$ is called the gain. The gain is equivalent to the regression coefficient for each frequency $\omega$. It measures the amplification of the frequency components of the $\mathrm{X}$-process to obtain the corresponding components of the Y-process. The gain is most easily calculated by rewriting (12) as

$$
|\mathrm{A}(\mathrm{z})|=\sqrt{|\mathrm{A}(\mathrm{z})|^{2}}=\sqrt{\mathrm{A}(\mathrm{z}) \mathrm{A}(\overline{\mathrm{z}})}
$$

where $\bar{z}$ is the conjugate complex of $z$, i.e. $\bar{z}=\mathrm{e}^{\mathrm{i} \omega}$. Thus, in order to calculate the gain, all we have to know is the sequence of the coefficients from (6).

\subsection{Our Estimation Methodology}

However, when estimating our spectra, the underlying economic model would have the general form:

$$
\mathrm{V}(\mathrm{L}) \mathrm{Y}_{\mathrm{t}}=\mathrm{U}(\mathrm{L}) \mathrm{X}_{\mathrm{t}}+\varepsilon_{\mathrm{t}}
$$

where

$$
\mathrm{V}(\mathrm{L})=\sum_{\mathrm{s}=0}^{\mathrm{p}} \mathrm{v}_{\mathrm{s}} \mathrm{L}^{\mathrm{s}},\left(\mathrm{v}_{0}=1\right) \text {, and } \mathrm{U}(\mathrm{L})=\sum_{\mathrm{r}=0}^{\mathrm{q}} \mathrm{u}_{\mathrm{r}} \mathrm{L}^{\mathrm{r}} \text {. }
$$

Thus. as long as all eigenvalues of the characteristic equation of $\mathrm{V}(\mathrm{L})$ are less than one, as they will be if $\mathrm{Y}_{\mathrm{t}}$ is stationary, we can write

$$
\mathrm{Y}_{\mathrm{t}}=\frac{\mathrm{U}(\mathrm{L})}{\mathrm{V}(\mathrm{L})} \mathrm{X}_{\mathrm{t}}+\frac{1}{\mathrm{~V}(\mathrm{~L})} \varepsilon_{\mathrm{t}}
$$

We are particularly interested in calculating the first ratio of eq. (15) in order to derive the gain:

$$
\frac{\mathrm{U}(\mathrm{L})}{\mathrm{V}(\mathrm{L})}=\mathrm{W}(\mathrm{L})
$$


where $W(L)=\sum_{j=0}^{k} w_{j} L^{j}$ is the weight function. In order

to calculate the sequence $\left(\mathrm{w}_{0}, \mathrm{w}_{1}, \ldots, \mathrm{w}_{\mathrm{n}}, \ldots\right)$ in terms of $\mathrm{u}_{\mathrm{r}}$ and $\mathrm{v}_{\mathrm{s}}$, we use the following relationship (Hendry, 1995; Laven and Shi, 1993):

$$
\left(\sum_{j=0}^{\infty} w_{j} L^{j}\right)\left(\sum_{s=0}^{p} v_{s} L^{s}\right)=\sum_{r=0}^{q} u_{r} L^{r}
$$

Thus, given the lag structure in (17), we generate the gain according to (13). This yields:

$$
r(z)=\sqrt{\sum_{j=0}^{k} w_{j} z^{j} \sum_{j=0}^{k} w_{j} z^{-j}}
$$

where $\mathrm{z}=\mathrm{e}^{-\mathrm{i} \omega}$.

\section{ECONOMETRIC IMPLEMENTATION: A TIME-VARYING APPROACH TO THE TERM STRUCTURE OF INTEREST RATES}

So far, we have described the case of time-invariant parameters only. We now look at the case where the parameters are time-variant, i.e. (14) changes to

$$
\mathrm{V}(\mathrm{L})_{\mathrm{t}} \mathrm{Y}_{\mathrm{t}}=\mathrm{U}(\mathrm{L})_{\mathrm{t}} \mathrm{X}_{\mathrm{t}}+\varepsilon_{\mathrm{t}}
$$

As long as the parameters do not converge, the lagstructure $\mathrm{W}(\mathrm{L})$ will be different for each point in time. From there, we derive the gain according to (18). That is our second innovation in this paper.

In what follows, we estimate (19) by Kalman filtering techniques. We have used the Kalman filter because we need to test certain hypotheses about the time-varying nature of the underlying parameters. It is entirely possible that the agents in the financial markets will change their behaviour, and hence the way in which interest rates are determined; depending on which policy regime or policy environment they find themselves. The Lucas critique in other words: if we change the way in which monetary policy is set, the way in which agents determine the relevant short and long term interest rates (and risk premia) will change.

We apply these techniques to analyse the frequency response behaviour UK interest rates over the period 1982 - 1998. This period includes the soft (adjustable) EMS, the "hard" EMS, the collapse of the ERM to wide bands, and the introduction of inflation targeting. It is important that we are able to take the consequences of all these regime changes into account. The advantage of the Kalman filter algorithm is that it assumes that agents form one-period ahead forecasts. These forecasts are then compared with the next observation. Then, according to the Kalman gain, the coefficients are updated in order to minimise the one period ahead forecast error. That property makes the Kalman filter particularly convenient for modelling behaviour in the financial markets (see also Garratt and Hall, 1997): it incorporates rational behaviour by market participants, in terms of their short-run forecasts. This we formalise in the following state space model:

$$
\mathrm{i}_{\mathrm{t}}=\mathrm{D}_{\mathrm{t}} \mathrm{Z}_{\mathrm{t}}+\varepsilon_{1, \mathrm{t}}
$$

where (20) is the measurement equation and

$$
\mathrm{D}_{\mathrm{t}}=\mathrm{D}_{\mathrm{t}-1}+\varepsilon_{2, \mathrm{t}}
$$

is the state (updating) equation. In (21), $i_{t}$ is the British two year interest rate, $Z_{t}$ is a set of significant variables (including lags), such as the British base rate (as the monetary instrument), the German two year interest rate (to represent the ERM influences), the British ten year interest rate, and the US two year interest rate (to represent the influences of the world capital markets). $D_{t}$ is the matrix of estimated parameters, including a "time-varying" constant to represent a time-varying country specific risk premium.

To estimate our term structure model, (20) and (21), we used monthly data from the Bank of England, Federal Reserve, and the Bundesbank. The sample runs from 1982:1 to $1998: 10$. We tested the updating algorithm (21), because it is clearly possible for agents to update their coefficients after a shock has occurred. This follows from the model of Lucas (1976). In this specification, we have observations for eq. (20) for 190 months. In the following section, we analyse the effects of one (significant) shock, namely the collapse of the ERM in 1992. We investigate the parameter changes before the shock, during the shock, after the shock; and compare them with the parameters at the end of the sample (1998:10). These different regression results then allow us to infer the changes in the gain and in the phase shift over different periods of time.

\section{EMPIRICAL RESULTS}

The measurement equation (20) has the following form for all periods:

$$
\begin{aligned}
& \mathrm{i}_{\mathrm{t}, 2}^{\text {brit }}=\alpha_{1, \mathrm{t}}+\alpha_{2, \mathrm{t}} \text { Base Rate }_{\mathrm{t}}+\alpha_{3, \mathrm{t}} \mathrm{i}_{\mathrm{t}, 2} \mathrm{ier}^{\mathrm{ger}}+\alpha_{4, \mathrm{t}} \mathrm{i}_{\mathrm{t}, 10}^{\text {brit }} \\
& +\alpha_{5, \mathrm{t}} \mathrm{i}_{\mathrm{t}, 2}^{\mathrm{US}}+\alpha_{6, \mathrm{t}} \text { Base Rate }_{\mathrm{t}-1}+\alpha_{7, \mathrm{t}} \mathrm{i}_{\mathrm{t}-1,2}^{\mathrm{brit}} \\
& +\alpha_{8, \mathrm{t}_{\mathrm{t}-1,2}}+\alpha_{9, \mathrm{t}} \mathrm{i}_{\mathrm{t}-1,10}^{\mathrm{brit}}+\varepsilon_{\mathrm{t}}
\end{aligned}
$$

where $\mathrm{i}_{\mathrm{t}, \mathrm{m}}^{\mathrm{a}}$ is the interest rate of country "a" (Britain, Germany, or the US) at time $t$, with a term to maturity of $m$ years. The derivation of the structural form and all tests can be found in Richter (2001). In this paper, we are particularly interested in the parameter values during the ERM turmoil. The following table gives the varying parameter values at different points in time these are the Kalman filter estimates obtained for (22). 
Table 1 Parameter Values for Different Points in Time

\begin{tabular}{cccccccccc}
\hline Time & $\alpha_{1}$ & $\alpha_{2}$ & $\alpha_{3}$ & $\alpha_{4}$ & $\alpha_{5}$ & $\alpha_{6}$ & $\alpha_{7}$ & $\alpha_{8}$ & $\alpha_{9}$ \\
\hline $92:$ & .58 & .43 & .03 & .44 & .57 & -.27 & .67 & -.34 & -.26 \\
08 & & & & & & & & & \\
$92:$ & .57 & .43 & .03 & .40 & .59 & -.27 & .66 & -.32 & -.25 \\
10 & & & & & & & & & \\
$93:$ & .57 & .44 & .03 & .39 & .59 & -.26 & .66 & -.32 & -.26 \\
01 & & & & & & & & & \\
$98:$ & .48 & .42 & .03 & .40 & .59 & -.29 & .68 & -.33 & -.28 \\
10 & & & & & & & & & \\
\hline
\end{tabular}

(Priestley, 1996) points out that interpreting a timedependent spectrum is not easy. For example, looking at 1998:10, variations in the base rate will cause cycles in the interest rates payable on bonds with two years maturity. Although these cycles may not have died down before some other shock or base rate change hits the system, it is still interesting to know what cycles have been caused in the short term. On the other hand, if the parameters do eventually converge, then the end of a cycle will be reached. In that case, the gain (and the phase angle) can be interpreted as their steady state or permanent values as usual.

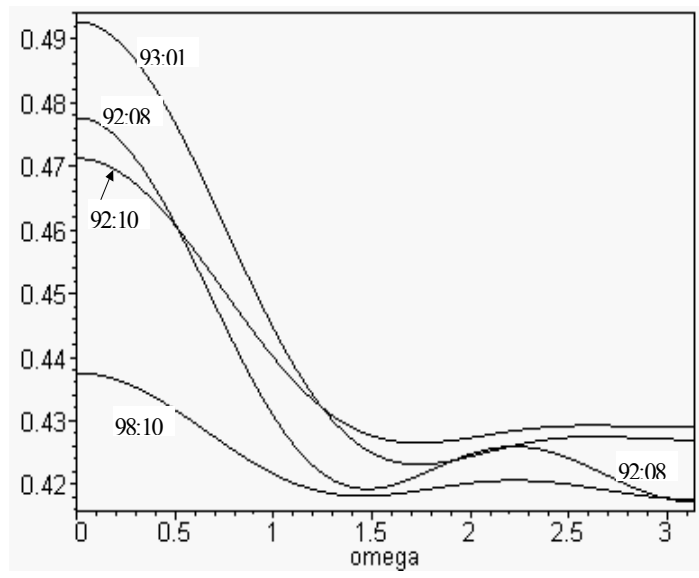

Fig. 1. Gains at Different Points in Time for the UK

Base Rate on the Interest Rate with a Maturity of Two Years

The calculated gains reported in figure 1, show that these cycles are stable (the gain "factor" is always less than unity) - nevertheless, changes in the UK base rate set up both long and short cycles in short term interest rates which have amplitudes of nearly half the size of the original movements in the base rate. However, the short cycles (less than 6 months in length) are clearly weaker than the long cycles which have a periodicity of 1 year and up. That shows that UK monetary policy has long term consequences for monetary conditions, in addition to any short run or immediate impact.

Of more interest perhaps are the results which show how these long and short term cyclical consequences changed in September 1992, around the ERM crisis.
Figure 1 demonstrates that the immediate effect was a reduction of the long-term value of the gain. However, the slope was also affected, i.e. shorter cycles gained weight, relative to longer cycles. That would reflect greater uncertainty or confusion. Hence, it can be concluded that the ERM crisis resulted in higher volatility. However, that effect did not last long: in January 1993 the long-term gains were higher than ever before. Nevertheless, short-term cycles were still important since the gain does not die out at the short end. Moreover, although a peak is still visible at the beginning of the curve for 1998:10, it is not as prominent as before. Monetary policy has therefore gradually lost efficiency over time, in the sense that it created greater short term volatility compared to a loss in its longer term "systematic" effects.

\section{CONCLUSION}

The main result is therefore that learning affects the volatility of observed time series. That reflects how agents try to anticipate what is going on in the market.

\section{REFERENCES}

Akerlof, G. (1970). The Market for Lemons: Qualitative Uncertainty and the Market Mechanism. Quarterly Journal of Economics, Vol. 89, pp. 488500.

Black, F. (1989). Noise. Journal of Finance, Vol. 48, pp. 540-555.

Easley, D. and O'Hara, M., (1992). Adverse Selection and Large Trade Volume: The Implications for Market Efficiency. Journal of Financial and Quantitative Analysis, Vol. 27, pp. 185-208.

Garratt, A. and Hall, S. G. (1997). E-equilibria and Adaptive Expectations: Output and Inflation in the LBS Model. Journal of Economic Dynamics and Control, Vol. 21, pp. 1149-1171.

Hendry, D. F. (1995). Dynamic Econometrics, Oxford University Press, Oxford.

Laven, G. and Shi, G. (1993). Zur Interpretation von Lagverteilungen, University of Mainz discussion paper, no. 41.

Nerlove, M., Gether, D. M., and Carvalho, J. L. (1995). Analysis of Economic Time Series, Academic Press, New York.

Priestley, M. B. (1996). Wavelets and Time-Dependent Spectral Analysis. Journal of Time Series Analysis, Vol. 17(1), pp. 85-103.

Richter, C. (2001). Learning and the Term Structure of Interest Rates in Britain and Germany, $\mathrm{PhD}$ Thesis, University of Strathlcyde in Glasgow.

Wolters, J. (1980). Stochastic Dynamic Properties of Linear Econometric Models, Springer Verlag, Berlin. 